\title{
Analysis on the Implementing Tactics of the Aid Mechanism for the University Students' Difficulty in Employment
}

\author{
Lixia Wang \\ Yunnan University of Traditional Chinese Medicine, Kunming, Yunnan, \\ 650500
}

\begin{abstract}
The overall characteristics of college students' employment difficulties are "employment", which leads to the unemployed, the optimal human capital unemployment and the underemployment of college graduates. The root cause of college students' employment difficulties is the depreciation of human capital stock, that is, the ability of human capital carriers to gain income, and weaken or disappear the capacity of income space. The essence is that the expected return on investment can not be obtained. The fact that university graduates are unemployed in our country belongs to the phenomenon of depreciation of human capital stock. It is concluded that the causes of the underprivileged groups include initial human capital investment decision-making mistakes, employer's avoidance of human capital investment, oversupply of human capital market, economic situation, the overall demand is shrinking, and the salary level needs to be revised. Keywords: Implementing Tactics, Aid Mechanism, Employment
\end{abstract}

\section{Introduction}

At present, Chinese higher education is in a planned economy to the market economy system, the elite education to popular education in the process of deepening the transition. At the same time, it is also a process of differentiation and reorganization of the interest relationship in the development of higher education. In this process, the employment of college students is difficult to become the focus of government and society as a whole. Especially in recent 
years, with the employment of university students increased year by year, as well as the global economic crisis in the context of economic development continues to slump, college students increasingly difficult to obtain employment. As the difficulties of employment of college students constitute a complex, diverse problems, with a typical low-level distribution of the typical characteristics of the current study of the causes of employment of college students in China, improve the employment assistance model for promoting the healthy development of economic and social and higher education Important practical significance.

\section{College students are in urgent need of employment difficulties}

Under the planned economy system, the allocation of college students' human resources is entirely government behavior, the implementation of unified package system., The number of college graduates to supply, the number of university graduates on the arrangements for employment. Because of the protection of the employment system, college students lack of employment competition and unemployment pressure for a long time, which cut off the ability and employment, equality and efficiency of the link between inhibition of the strong, protect the weak. In this system, there is neither employment of college students difficult, there is no difficulty in employment groups. When the planned economy to a market economy transition, the employment system from the plan to the market configuration changes, the competition mechanism began to play a leading role in the process of employment of college students, the original out of the efficiency of the supply exceeds demand or difficult to adapt to market demand Students will be released 'out of college students will not be completely unemployed. Of course, the employment of college students is relatively difficult, not every college students have employment difficulties; different individuals, different types of schools, different professional graduates employment difficulties and employment quality showed significant differences. Therefore, the employment difficulties of college students are mainly as part of the employment patterns of groups, rather than the employment situation of the entire group of university students.

In recent years, the government and universities have so much attention to the employment difficulties of college students assistance, on the one hand because college students employment is difficult to a large extent refers to the employment of disadvantaged groups of employment status, effective promotion of employment difficulties group is to solve the employment difficulties On the other hand, because if the university graduates show a group of continuing unemployment or unemployment, whether for individual development or social development, the negative impact is self-evident. For a long time, people have been hoping to change their disadvantaged position in the social stratum by accepting higher education. However, college students from the disadvantaged in society are often in difficulty because of family economic difficulties, lack of social capital and overall quality. The main body of the group, in particular the continuing unemployment or employment difficulties due to non-self factors, can 
seriously undermine their confidence in access to quality employment through higher education. When the difficulty of employment is not a small number of cases but a group phenomenon, it will affect people's enthusiasm for investing in higher education on a large scale. At the same time, a large number of graduates unemployed or not full employment, not only affect the economic sustainable development and social harmony and stability, but also lead to human resources and higher education resources waste. From an economic point of view, college students' employment difficulties are inefficient behavior of human resources allocation, which limits the opportunities for college students to contribute to society. From the sociological point of view, employment difficulties make individual higher education investment not timely return, which may lead to Employment environment and employment system dissatisfaction, the formation of social instability.

\section{Analysis of Group and Institutional Characteristics}

From the attribute point of view, the elastic or rigid employment difficulties; from the distribution point of view, whereabouts scattered $\$$ elasticity of employment difficulties are mainly reflected in the mentality: pick and choose, eye low, ambitious, afraid of fear tired, lazy negative $\$$ college students And some parents have no idea of the employment of children after 80 , and then wait for the idea, and some parents are not satisfied with the job, In the process of employment, students rely on, to, state, rigid college students employment difficulties are mainly reflected in the ability. Some of them have not obtained the required degree certificates, diplomas, vocational qualification certificates and other relevant documents, lack of learning ability, can not complete the established academic tasks; some low employability, The majority of employers believe that the graduates to work, the actual utilization of knowledge is low, and most of the practical ability of students practical ability to address the practical problems of poor work. ; Some difficulties in employment and family financial difficulties to the main performance of $\$$ scattered after graduation they go their separate ways, and some return home unemployed, and some drifting city to become) ant family. The two characteristics of the aid system: the system of long and convergence of the first few.

At present, various localities have introduced or improved various aid systems to help college students find jobs. Guangdong Provincial Development and Reform Commission in Guangdong Province employment, "Eleventh Five-Year Plan" pointed out that the current system of employment assistance to improve the current re-employment of older groups for the special support policies, adjustment to other towns and rural areas of employment difficulties Povertystricken families, the establishment of urban and rural employment difficulties covering the policy measures and operational mechanisms. In 2007, Heilongjiang Province, the economic difficulties of the family and employment difficulties of graduates to give employment assistance to the difficulties of family employment assistance for employment of graduates into government assistance to 
disadvantaged groups of employment policy system In 2009, the Hunan Provincial Government announced employment assistance for college graduates Policies and measures, through one-on-one employment guidance, to the employer focused recommendation, the placement of public welfare and other supporting measures to help the unemployed college graduates after graduation employment, according to the provisions of the implementation of public welfare subsidies, social insurance subsidies and other employment Aid policy. From the department point of view, there are party or mission organizations, educational administration, human resources and social security departments, financial sector, science and technology departments, civil affairs departments issued employment assistance policy of college students, from the time span point of view, will have assistance in different months The issuance of the policy, the long reflected in the release of the main and the time span, and a small head mainly reflected in the system and more in the form of the region or sector, has not formed a multisectoral or multi-regional linkage package, release time is still scattered Stage, did not form enough influence and effectiveness.

\section{Institutional Innovation Path of Employment Assistance for College Students}

At present, the employment assistance model of single subject has been very difficult to adapt to the reality of the gradual expansion of the employment difficulties of college students. The government, universities and society as a whole should devote more energy to help them get a job, and through the innovation aid system, it will form a responsibility system which can benefit every student with difficulties in employment and cooperation. First, the rational planning of industrial restructuring and the relationship is between the employment of college students. The quality of industrial structure transformation determines the optimization of industrial structure and the transformation of economic growth mode, which determines the structure of employment and the distribution of graduates. To effectively enhance the ability of economic development to absorb the employment of college students, we must combine the adjustment of industrial structure and technology upgrading and solve the employment problem of college students, and arrange the relationship between economic development planning, talent team planning and college students' employment. Second, the department in charge of education should take the lead in coordinating the relationship between other relevant departments of the government, perfecting the division of responsibility and leadership and coordinating mechanism for the assistance of the disadvantaged groups of university students; strengthening the coordination and communication between the government and universities, industry enterprises and the labor market; , Give full play to the power of all sectors of society to participate in employment assistance to college students. Thirdly, the university should combine the assistance of the disadvantaged groups of college students with the reform of 
talent cultivation mode, employment guidance and career development planning, carry out targeted employment services, and continuously improve the employment quality and employability of college students.

The experience of western market economy countries shows that market regulation and government support are the fundamental ways to solve the employment problem. With the transition from employment system to marketization and socialization mechanism, the non-employment difficulties students should be solved by the spontaneous mechanism of the labor market, while the disadvantaged or the disadvantaged groups need the government's concern and help. Relatively speaking, the government is the coordinator of social interests, the host of fiscal redistribution, the government's responsibility for the disadvantaged and quasi-vulnerable workers, as well as the financial, administrative, and policy instruments to accomplish this task, Government regulation and market regulation complement each other, with the use of, can maximize the quality and effectiveness of employment assistance to college students. First, the Government's macro-control aims to promote industrial restructuring, opening up new jobs: First, the use of China's economic growth mode of transformation of the current development opportunities, increase the industrial restructuring and technological transformation of enterprises to support efforts, through regional industrial restructuring, To create more employment opportunities for college students, especially those with difficulty in employment; secondly, to purchase and create jobs directly, and to make up for the shortage of employment opportunities for college students through the implementation of public employment projects. Secondly, by strengthening the labor market construction, optimize the allocation of university students' human resources: First, remove the obstacles to the rational flow of college students obstacles to the establishment of a unified job market for college students. The key issue now is to break the boundaries of urban and rural areas, household registration, regional, industry, ownership and so on, to eliminate barriers to the employment market, and promote the free flow of employment of college students; the second is to establish a smooth university employment information system and standardized and orderly employment service system, And perfect the legal supervision of employment system to ensure the orderly operation of the employment market for college students to protect the legitimate rights and interests of employment groups.

\section{Conclusion}

The four strategies proposed in this paper are both macroscopical and microcosmic, which is the method and art of implementing the system. The system propaganda strategy starts from the seven elements to promote the system, and the graded response strategy divides the assistance priorities from two dimensions, It is helpful to construct a complete set of social employment service system so that the whole society can participate in and care about the difficult employment groups of college students, which is conducive to the formation of a 
complete employment information. In this way, it is helpful to form a comprehensive employment information system. Feedback system, so that the system can be consistent.

\section{References}

[1] Huang Jingbao.Study on employment situation of undergraduates in Beijing in 2008. Chinese Youth Research, 1(2), pp. 31-33, 2009.

[2] Luo Bi-chun.Study on the Employment Guidance of College Students from the Perspective of Career Component Elements .Business Culture, 12(2), pp. 3133, 2008 .

[3] Liu Yan, the interests of college students in the employment process maintenance. Law and Society, 12(4), pp. 32-41, 2012.

[4] Luo Xiu.From the supply and demand of the talent market to see the employment space expansion of college students .China Adult Education, 8(1), pp. 32-34, 2009.

[5] Dong Zhi. From the perspective of information asymmetry and employment risk of college students employment problem. Journal of Shanxi Finance and Economics University, 3(2), pp. 44-48, 2008. 